\title{
Refractory cytopenia with multilineage dysplasia
}

INSERM

\section{Source}

INSERM. (1999). Orphanet: an online rare disease and orphan drug data base. Refractory cytopenia with multilineage dysplasia. ORPHA:86836

Refractory cytopenias with multilineage dysplasia (RCMD) is a frequent subtype of myelodysplastic syndrome (MDS; see this term) characterized by 1 or more cytopenias in the peripheral blood and dysplasia in 2 or more myeloid lineages. 